\title{
Impact of disaggregation of composite foods on estimates of Eatwell plate proportions in the diets of adults in Scotland
}

\author{
S. Whybrow ${ }^{1}$, JI. Macdiarmid ${ }^{1}$ and G. McNeill ${ }^{2}$ \\ ${ }^{1}$ Rowett Institute of Nutrition and Health and ${ }^{2}$ Public Health Nutrition Research Group, University of Aberdeen, \\ Aberdeen AB25 2ZD
}

In the UK, the Eatwell Plate was developed to provide a consistent message to the public about how to achieve a healthy balanced $\operatorname{diet}^{(1)}$. The Eatwell plate is a food-based visual representation of the balance of five food groups: bread, rice, potatoes, pasta and other starchy foods (starchy), fruit and vegetables (F\&V), milk and dairy foods (dairy), meat, fish, eggs, beans and other non-dairy sources of protein (protein) and foods and drinks high in fat and/or sugar (HFHS) ${ }^{(1)}$. Manufactured, and homemade, dishes typically comprise ingredients from several food groups; consumers and researchers must consider how these fit with the proportions of the Eatwell plate. This involves disaggregating composite dishes into proportions of individual food components. Meat intake is overestimated by not disaggregating the meat content from composite dishes ${ }^{(2,3)}$ but the implications for other food groups, and for the Eatwell plate, are unknown.

The aim of this study was to explore how the estimated Eatwell plate proportions of typical diets change when composite foods are disaggregated into Eatwell plate food groups.

Dietary data were taken from two existing studies in which adult subjects $(161 \mathrm{~F}$ and $151 \mathrm{M})$ reported their normal diets by weighed food intake records. Each food and beverage was assigned to a single Eatwell food group, based on the main ingredient for composite foods, and the overall Eatwell plate proportions of each subject's diet calculated. Weights of milk and fruit juices were halved, and sugar sweetened beverages taken as the weight of their sugar content only. The food group proportions were then recalculated after disaggregating composite foods using estimates from representative recipes taken from food composition tables, similar foods and dishes, or from internet sources.

\begin{tabular}{|c|c|c|c|c|c|}
\hline & Eatwell Starchy & Eatwell F\&V & Eatwell Dairy & Eatwell Protein & Eatwell HFHS \\
\hline Without disaggregation (g/d) & 372 & 399 & 200 & 216 & 175 \\
\hline With disaggregation $(\mathrm{g} / \mathrm{d})$ & 354 & 442 & 207 & 165 & 219 \\
\hline $\mathrm{P}$ & $0 \cdot 177$ & $0 \cdot 029$ & $0 \cdot 535$ & $<0.001$ & $<0.001$ \\
\hline Recommended \% & 33 & 33 & 15 & 12 & 8 \\
\hline$\%$ without disaggregation & $27 \cdot 6$ & $28 \cdot 3$ & $14 \cdot 3$ & $16 \cdot 3$ & $13 \cdot 5$ \\
\hline$\%$ with disaggregation & $25 \cdot 7$ & $30 \cdot 9$ & $14 \cdot 6$ & $12 \cdot 2$ & $16 \cdot 5$ \\
\hline $\mathrm{P}$ & $0 \cdot 008$ & 0.006 & $0 \cdot 584$ & $<0 \cdot 001$ & $<0.001$ \\
\hline
\end{tabular}

Failing to disaggregate foods resulted in an overestimate of the amount $(\mathrm{g} / \mathrm{d})$ of protein foods (which includes meat and meat based products), and an underestimate of the amount of F\&V and HFHS foods in subjects' diets. This resulted in differences in all but the dairy Eatwell plate proportions. Average F\&V intake may be higher, and closer to recommended levels, than is often reported because of the "hidden" contribution of F\&V in composite foods.

Not disaggregating composite foods and dishes distorts the apparent quality of the diet when compared against the recommended Eatwell plate proportion.

1. Food Standards Agency (2010) The eatwell plate.

2. Cosgrove M, Flynn A \& M (2004) Public Health Nutrition, 8 (3), 327-337.

3. Prynne C, Wagemakers J, Stephen A, et al. (2009) European Journal of Clinical Nutrition 63, 660-666.

4. Stubbs R, O'Reilly L, Whybrow S et al. (2014) British Journal of Nutrition 111, 2032-2043

5. Whybrow S, Mayer C, Kirk T et al. (2007) Obesity Research 15, 673-685. 